\title{
SUITABILITY OF CRUSHER-DUST AS MASONRY CONSTRUCTION MATERIAL
}

\author{
Dr-Ing. John K. Makunza \\ Department of Structural Engineering \\ University of Dar es Salaam
}

\begin{abstract}
C rusher dust generated at Kunduchi quarries in Dar es Salaam during aggregate crushing is counted as a waste material, and some times it is disposed away or sold at a cheap price of not more than a quarter of that of sand. A study on the use of the crusher dust as a building material has been carried out in which samples were collected and analyzed for grading (sieve analysis). In additional to that, other samples were stabilized with a small amount of cement, from which bricks were produced and tested for compressive strength. Other bricks were bonded together using mortar which had the same ratio of cement to crusher dust as that which was used for manufacturing the bricks. Then both the bricks and the walls were tested for compressive strength. The results obtained from sieve analysis as well as compressive strengths have shown that the crusher dust masonry is a suitable building material which leads to lower cost of the walls if compared to concrete blocks.
\end{abstract}

Key words: Crusher dust, grading, mould, bricks, mortar, strength.

\section{INTRODUCTION}

Masonry has been used for the construction of buildings for thousands of years and it has been the most widely used material in civil engineering buildings. For instance, most of the ancient historical buildings in Egypt, Mesopotamia, etc, or old transport engineering structures are made up of masonry. It is believed that at around $4000 \mathrm{BC}$, the secret of masonry arch construction was discovered, and was firstly applied in the valley of rivers Tigris and Euphrates in Mesopotamia[1]. These structures have withstood the test of time in terms of their structural competence. Improvements in the knowledge and understanding of the material properties of masonry of all types has resulted in the dimensions of modern structures built using masonry.

Although the term "masonry" refers to various kinds of bonded together materials with different mechanical responses, it can always be regarded as a composite material, where a collection of units such as stones, clay bricks, concrete blocks, ect, are arranged and bonded with mortar. Its mechanical properties inherit from its composite nature in a complex behavior which depends on a strong non-linear combination of the shape, size and mechanical properties of elements or parts of its microstructure.

Crusher dust generated at Kunduchi quarries during aggregate crushing is counted as a waste material, and some times it is disposed away. A study on the economic use of the crusher dust has been carried out in which samples were collected and analyzed for particles size distribution (sieve analysis), the results obtained have shown that it is well graded. Two categories of bricks were made from stabilized crusher dust. Category one bricks were manufactured from stabilized soil[2] at a ratio of 1:10 ( 1 part cement :10 parts crusher dust), and category two was produced from stabilization ratio of 1:15 (1 part cement : 15 parts crusher dust). After 28 days, some bricks were tested and others were built into wall specimens. The mortar used for bonding had the same ratio of cement to crusher dust as that which was used for the manufacture of the respective bricks. The mortar as well as the walls were tested and the results have shown that the crusher dust masonry is a suitable building material which leads to lower cost of the walls if compared to concrete blocks. 


\section{OBJECTIVES}

The objective of the research was to study the properties of bricks manufactured from crusher dust in order to see whether they can be suitable building materials, otherwise. This was done by testing the crusher dust, the bricks made from it and the mortar used to bond the bricks into specimen walls, and by testing the wall specimens.

\section{OVERVIEW}

Brick masonry is composed of two materials

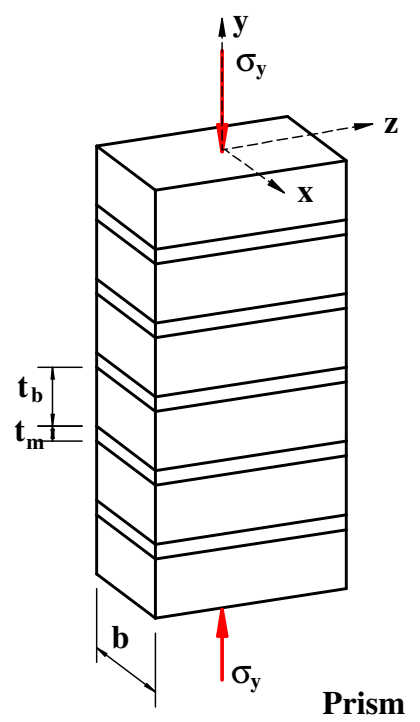

with quite different properties; relatively soft mortar and high pressed bricks[3]. When the brick work is subjected to uniaxial compressive force, the mortar has a tendency of expanding terally more than the brick. Since the mortar and bricks are bonded together chemically and mechanically, the mortar is confined laterally by the brick. Shear stresses at the brick-mortar interface result in an internal state of stress which consists of triaxial compression in the brick. as illustrated in Figure 1.
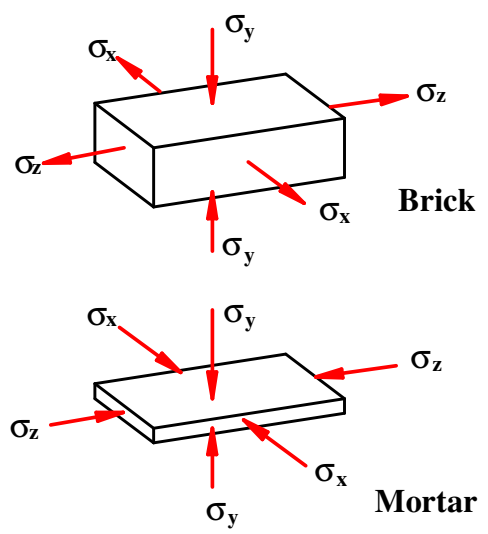

Figure 1: Prism subjected to vertical compressive force and stress state in brick and mortar

A theory has been developed [4] that characterizes the strength and deformation properties of stack-bond prisms loaded in compression. It is a description of behavior based on strain compatibility at the brickmortar interface. The theory is simplified by considering nominal average stresses over the thickness of brick mortar. The model differs from previous failure theories because the effects of the nonlinear behavior of mortar are included. According to the theory proposed by Atkinson[4], the lateral stresses in the brick can be expressed as:

$$
\Delta \sigma_{x b}=\frac{\Delta \sigma_{y}\left[v_{b}-\frac{E_{b}}{E_{m}\left(\sigma_{1}, \sigma_{3}\right)} v_{m}\left(\sigma_{1}, \sigma_{3}\right)\right]}{\left[1+\frac{E_{b}}{E_{m}\left(\sigma_{1}, \sigma_{3}\right)} \frac{t_{b}}{t_{m}}-v_{b}-\frac{E_{b}}{E_{m}\left(\sigma_{1}, \sigma_{3}\right)} \frac{t_{b}}{t_{m}} v_{m}\left(\sigma_{1}, \sigma_{3}\right)\right]}
$$

where

$$
\begin{array}{lll}
\Delta \sigma_{\mathrm{xb}}= & \text { increment of lateral stress in the brick } \\
\Delta \sigma_{\mathrm{y}}= & \text { increment of vertical stress in the prism } \\
v_{b}= & \text { Poison's ratio of the brick } \\
\mathrm{E}_{\mathrm{b}}= & \text { Young's modulus of the brick } \\
v_{m}\left(\sigma_{1}, \sigma_{3}\right)= & \text { Poison's ratio of mortar as a function of principal stresses } \\
\mathrm{E}_{\mathrm{m}}\left(\sigma_{1}, \sigma_{3}\right)= & \text { Young's modulus of mortar as a function of principal stresses } \\
\mathrm{t}_{\mathrm{b}} & = & \text { thickness or height of the brick } \\
\mathrm{t}_{\mathrm{m}}= & \text { thickness of mortar bed joint }
\end{array}
$$


Equation (1) describes the increment of lateral stress in the brick, $\Delta \sigma_{\mathbf{x b}}$, resulting from an increment of compressive stress, $\Delta \sigma_{\mathrm{y}}$. The lateral stress in the brick is a function of the material properties of the brick and mortar. Poisson's ratio $\boldsymbol{v}_{m}$ and Young's modulus $\boldsymbol{E}_{m}$, of the mortar are expressed as a function of the vertical stress $\sigma_{1}$ and the lateral stress $\sigma_{3}$. This accounts for the non-linear properties of the mortar with respect to the existing state of stresses. The properties of the brick are assumed to be constant under all stress states.

The magnitude of the vertical load significantly controls the failure of masonry walls and columns. The failure may be one among the following three scenarios:

\section{Low axial load - Failure in the horizontal bed joint}

The effective friction is a minimum with smaller stresses $\sigma_{2}$ tend to slide due to shear. Since $\sigma_{2}$ is located on the diagonal of the units, a stepped crack appears in the wall following the joints.

\section{Moderate axial load - Tensile cracking of the unit}

With a larger vertical load, the friction resistance in the joint also becomes larger. In this case a crack may develop at the center of the unit due to the inclined principal tensile stresses if these exceed the tensile strength of the units.

\section{High axial load - Compressive failure of the wall}

Large vertical stresses in combination with shear stresses may results in large principal compressive stresses which can lead to compressive failure.

\section{THE INVESTIGATION}

\subsection{Materials}

The crusher dust material was collected from Kunduchi quarries in the suburbs of the city of
Dar es Salaam. The crusher dust was then sieved through a $2.36 \mathrm{~mm}$ sieve. The passed material was subjected to the sieve analysis in order to assess the particles grading. The sieve sizes ranged from $0.075 \mathrm{~mm}$ to $2.36 \mathrm{~mm}$. After sieving and analyzing the results, it was observed that most of the crusher dust material had their particle size distribution between 0.15 $\mathrm{mm}$ and $2.36 \mathrm{~mm}$. This range of particle size distribution, according to USCS soil classification, the crusher dust material is medium sand. The results from sieve analysis are presented in Figure 3.

\section{Soil Stabilization}

The crusher dust soil was stabilized using a small amount of cement in order to improve the bonding and strength properties. Two ratios were chosen; these were 1:10 and 1:15 (1 part cement to 10 or 15 parts crusher dust). These ratios were chosen to reflect smaller amount of cement in comparison with the traditional methods of cement blocks production in which the ratios are between 1:8 and 1:10.

\section{Production of bricks and tests}

The stabilized soil was then mixed with an appropriate amount of water which was a water-cement ratio of around 0.4. After thoroughly mixing by hand, the moist mixture was filled in a brick steel mould which can exert high compressive pressure by pressing down the lever arm handle (see Figure 2). After pressing, the mould was opened, then the brick was pushed-up and finally taken out for staking. The process was repeated for each brick from both mix ratios till the required number of bricks was attained. The bricks were cured by sprinkling water for 7 days, then they were left to mature in strength. After reaching an age of 28 days the bricks were subjected to various tests as shown in the next sections. 


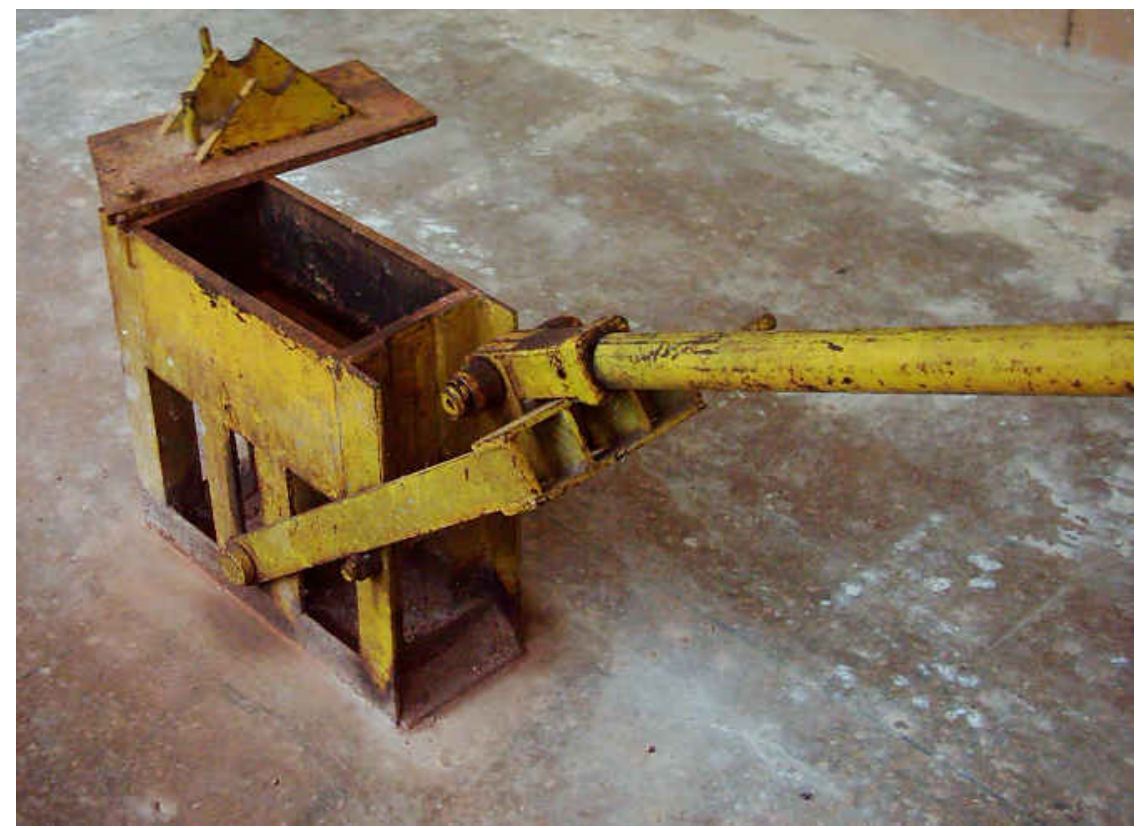

Figure 2: Mould for brick manufacturing

\subsection{Results}

(a) Sieve analysis results

CRUSHER DUST SIEVE ANALYSIS

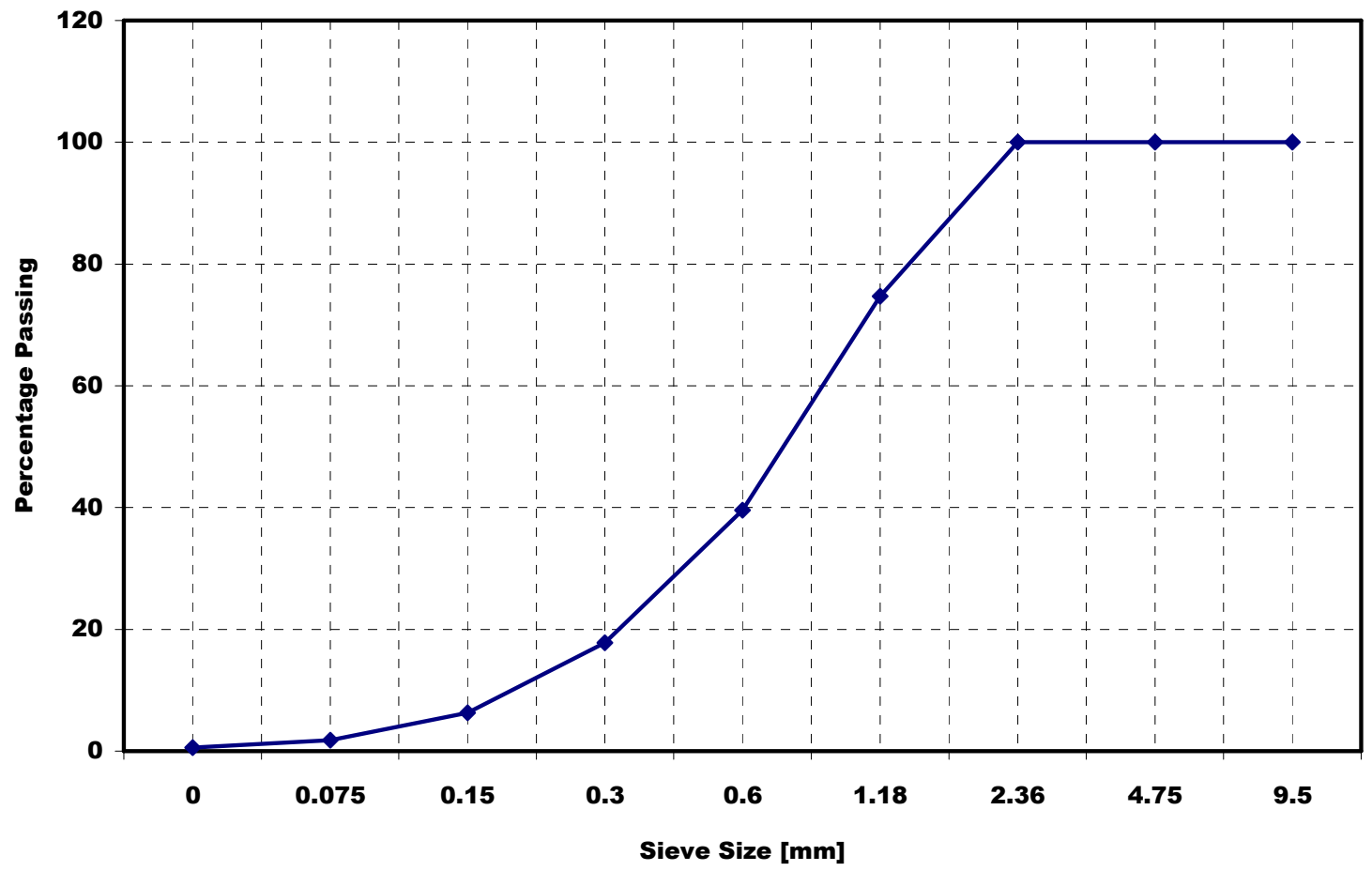

Figure 3: $\quad$ Crusher dust sieve analysis curve (MS -medium sand)

Compressive strength of bricks (1:10 mix ratio)

A total number of 4 bricks were sampled for testing using the compression test machine.
The bricks were first measured of their actual sizes and weights. Then each brick was tested for the compressive strength, the results of which are shown in Table 1. 
Table 1: Compressive Strength of bricks (1:10 ratio)

\begin{tabular}{|c|c|c|c|c|c|c|c|c|}
\hline $\begin{array}{c}\text { Brick } \\
\text { Sample } \\
\text { No. }\end{array}$ & \multicolumn{3}{|c|}{$\begin{array}{c}\text { Dimensions } \\
{[\mathrm{mm}]}\end{array}$} & $\begin{array}{c}\text { Weight } \\
{[\mathrm{kg}]}\end{array}$ & $\begin{array}{c}\text { Density } \\
{\left[\mathrm{kg} / \mathrm{m}^{3}\right]}\end{array}$ & $\begin{array}{c}\text { Area of } \\
\text { Compression } \\
{\left[\mathrm{mm}^{2}\right]}\end{array}$ & $\begin{array}{c}\text { Failure } \\
\text { Load } \\
{[\mathrm{kN}]}\end{array}$ & $\begin{array}{c}\text { Compressive } \\
\text { Stress } \\
{\left[\mathrm{N} / \mathrm{mm}^{2}\right]}\end{array}$ \\
\hline \hline 1 & 300 & 140 & 100 & 7.655 & 1822.6 & 42000 & 135 & 3.21 \\
\hline 2 & 300 & 140 & 100 & 7.848 & 1868.6 & 42000 & 160 & 3.81 \\
\hline 3 & 300 & 140 & 100 & 7.768 & 1849.5 & 42000 & 142 & 3.38 \\
\hline 4 & 300 & 140 & 100 & 7.773 & 1850.7 & 42000 & 150 & 3.57 \\
\hline \multicolumn{3}{|c|}{ Average value } & $\mathbf{1 8 4 7 . 9}$ & & 3.49 \\
\hline
\end{tabular}

The strengths of all bricks fall within the first two values adopted by BS 5628[5] Part 1: Table 2 for blocks in which the first 3 low values are 2.8 $\mathrm{N} / \mathrm{mm}^{2}, 3.5 \mathrm{~N} / \mathrm{mm}^{2}$ and $5.0 \mathrm{~N} / \mathrm{mm}^{2}$.

\section{Compressive strength of walls (1:10 mix ratio)}

A total of 5 wall specimens were built using mortar of the same cement-crusher dust ratio as that for bricks production. The specimens were of 5 brick courses high and 2.5 lengths of a brick. The walls were cured for 7 days, after which they were left to mature in strength development. Tests were carried-out after the walls had reached an age of 28 days. For each wall, displacements at $5 \mathrm{kN}$ intervals of load increments were taken. The obtained loaddisplacement curves of all walls are presented in Figure 4. The walls compressive stress results are given in Figure 5.

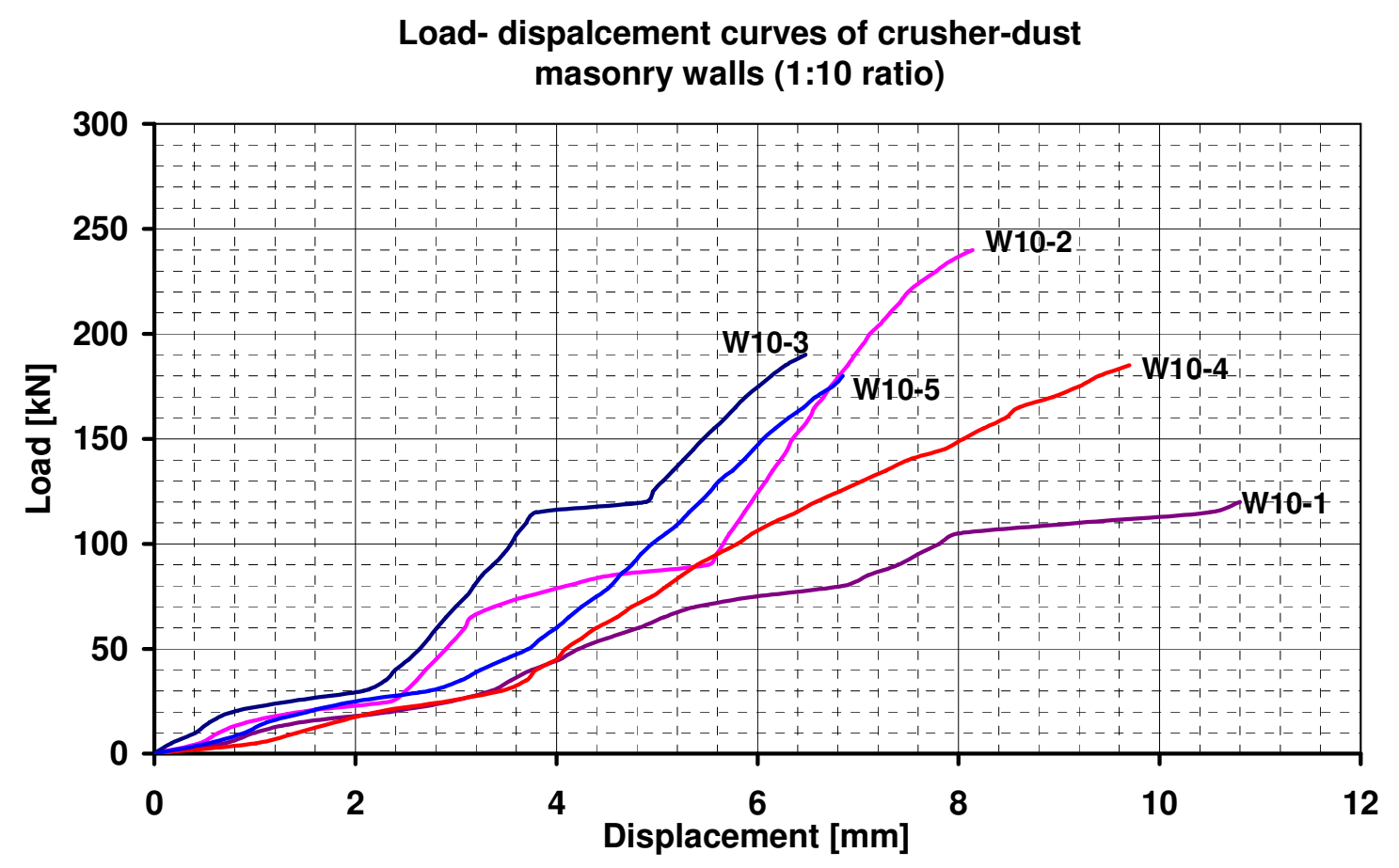

Key: $\mathrm{W} 10-\mathrm{n}: \mathrm{w}=$ wall specimen, $10=$ from bricks of $1: 10$ mix ratio, $\mathrm{n}=$ sample number.

Figure 4: Graphical results for wall tests 


\section{Compressive Strength of Walls [ratio 1:10]}

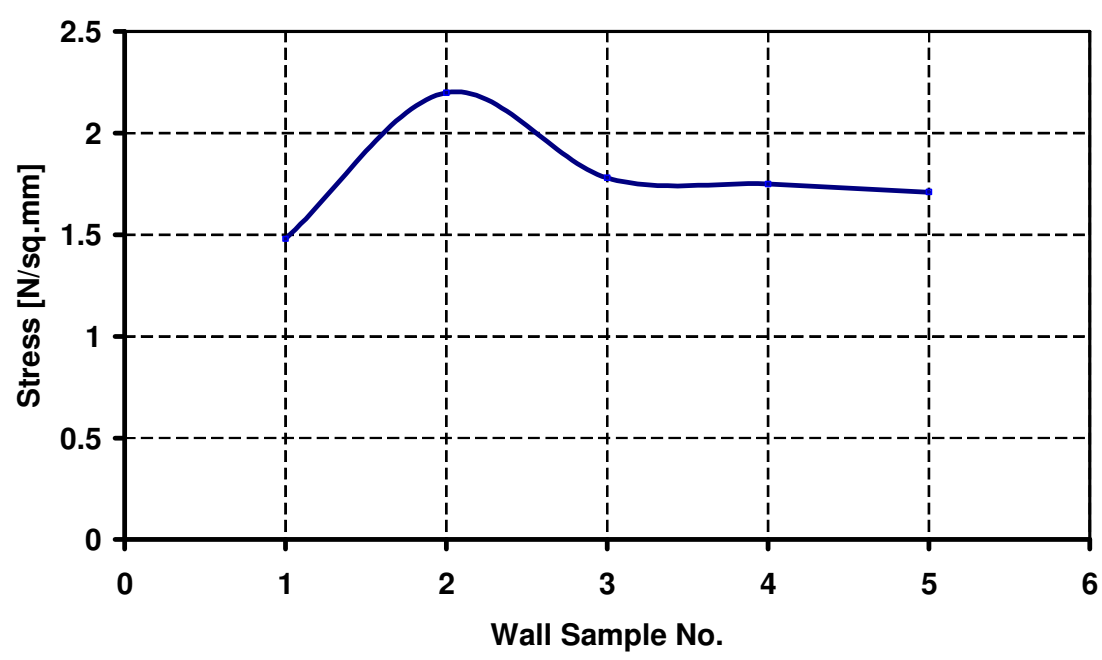

Figure 5: Strength of walls - ratio 1:10

From BS 5628 Part 1, the characteristic strength of masonry in any grade of mortar for masonry units of strengths $2.8 \mathrm{~N} / \mathrm{mm}^{2}$ and $3.5 \mathrm{~N} / \mathrm{mm}^{2}$ are $1.4 \mathrm{~N} / \mathrm{mm}^{2}$ and $1.7 \mathrm{~N} / \mathrm{mm}^{2}$ respectively. Therefore, the compressive strength of the tested walls fall within the first 2 lowest values in BS 5628 Part 1; Table 2, hence the crusherdust masonry bricks qualify as structural units.
Compressive strength of mortar (1:10 ratio)

The mortar used to bond together the bricks was made from a mixture of cement and crusher dust of the same ratio as the mix used to manufacture the bricks. A total of 3 cubes of $100 \mathrm{~mm}$ sides were prepared and cured for 7 days. After reaching an age of 28 days they were tested for their compressive strengths, the results of which are shown in Table 2.

Table 2: $\quad$ Compressive strength of mortar (1:10 ratio)

\begin{tabular}{|c|c|c|c|c|c|c|c|c|}
\hline \multirow[t]{2}{*}{$\begin{array}{c}\text { Sample } \\
\text { No. }\end{array}$} & \multicolumn{3}{|c|}{$\begin{array}{l}\text { Dimensions } \\
{[\mathrm{mm}]}\end{array}$} & \multirow[t]{2}{*}{$\begin{array}{r}\text { Weight } \\
{[\mathrm{kg}]}\end{array}$} & \multirow[t]{2}{*}{$\begin{array}{l}\text { Density } \\
{\left[\mathrm{kg} / \mathrm{m}^{3}\right]}\end{array}$} & \multirow{2}{*}{$\begin{array}{c}\text { Area of } \\
\text { Compression } \\
{\left[\mathrm{mm}^{2}\right]}\end{array}$} & \multirow{2}{*}{$\begin{array}{c}\text { Failure } \\
\text { Load } \\
{[\mathrm{kN}]}\end{array}$} & \multirow[t]{2}{*}{$\begin{array}{c}\text { Compressive } \\
\text { Stress }\left[\mathrm{N} / \mathrm{mm}^{2}\right]\end{array}$} \\
\hline & $a$ & $\mathrm{~b}$ & $\mathrm{~h}$ & & & & & \\
\hline 1 & 101 & 100 & 100 & 1.631 & 1615 & 10100 & $\begin{array}{l}13.0 \\
\end{array}$ & 1.29 \\
\hline 2 & 101 & 100 & 100 & 1.629 & 1613 & 10100 & 14.0 & 1.39 \\
\hline 3 & 100 & 100 & 100 & 1.627 & 1612 & 10000 & 12.6 & 1.26 \\
\hline \multicolumn{5}{|c|}{ Average value } & 1613 & & & 1.31 \\
\hline
\end{tabular}

The mortar is sufficiently strong to bond the crusher dust bricks without any problem as it has slightly lower compressive strength than the wall specimens.

\section{Compressive strength of bricks (1:15 mix ratio)}

As pointed out earlier, the second sample study was done by changing the amount of cement from a ratio of 1:10 to 1:15 (1 part cement to 15 parts crusher dust). In this case, again tests were performed on the individual bricks, wall specimens as well as the mortar cubes. A total of 9 bricks were randomly sampled and tested for their compressive strength using the universal compression machine. The results are shown in Table 3.

A close look at the bricks compressive strengths in Table 3, has revealed that only one value of $2.62 \mathrm{~N} / \mathrm{mm}^{2}$ out of 9 is below the specified minimum value of $2.8 \mathrm{~N} / \mathrm{mm}^{2}$ given by BS 5628 Part $1^{[5]}$. This low value may be attributed by variation in the compression effort during the brick manufacturing process. 
Table 3: Individual bricks compressive strength (1:15 ratio)

\begin{tabular}{|c|c|c|c|c|c|c|c|c|}
\hline \multirow{2}{*}{$\begin{array}{c}\text { Brick } \\
\text { sample } \\
\text { No. }\end{array}$} & \multicolumn{3}{|c|}{$\begin{array}{l}\text { Dimensions } \\
{[\mathrm{mm}]}\end{array}$} & \multirow{2}{*}{$\begin{array}{c}\text { Weig } \\
\mathrm{ht} \\
{[\mathrm{kg}]}\end{array}$} & \multirow{2}{*}{$\begin{array}{c}\text { Density } \\
{\left[\mathrm{kg} / \mathrm{m}^{3}\right.} \\
]\end{array}$} & \multirow{2}{*}{$\begin{array}{l}\text { Compressio } \\
\mathrm{n} \\
\text { Area }\left[\mathrm{mm}^{2}\right]\end{array}$} & \multirow{2}{*}{$\begin{array}{c}\text { Failure } \\
\text { load } \\
{[\mathrm{kN}]}\end{array}$} & \multirow{2}{*}{$\begin{array}{c}\text { Compressiv } \\
\text { e } \\
\text { stress } \\
{\left[\mathrm{N} / \mathrm{mm}^{2}\right]}\end{array}$} \\
\hline & $\mathrm{a}$ & $\mathrm{b}$ & C & & & & & \\
\hline 1 & 300 & 140 & 100 & 7.414 & 1765.2 & 42000 & 120 & 2.86 \\
\hline 2 & 300 & 140 & 100 & 7.875 & 1875.0 & 42000 & 120 & 2.86 \\
\hline 3 & 300 & 140 & 100 & 7.704 & 1834.3 & 42000 & 150 & 3.57 \\
\hline 4 & 300 & 140 & 100 & 7.558 & 1799.5 & 42000 & 125 & 2.98 \\
\hline 5 & 300 & 140 & 100 & 7.623 & 1815.0 & 42000 & 125 & 2.98 \\
\hline 6 & 300 & 140 & 100 & 7.369 & 1754.5 & 42000 & 110 & 2.62 \\
\hline 7 & 300 & 140 & 100 & 7.852 & 1869.5 & 42000 & 165 & 3.93 \\
\hline 8 & 300 & 140 & 100 & 7.631 & 1816.9 & 42000 & 140 & 3.33 \\
\hline 9 & 300 & 140 & 100 & 8.025 & 1910.7 & 42000 & 155 & 3.69 \\
\hline \multicolumn{5}{|c|}{ Average } & 1826.5 & & & 3.20 \\
\hline
\end{tabular}

\section{Compressive strength of walls (1:15 mix ratio)}

Four walls were built using a mortar which had the same mix ratio as the one used to manufacture the bricks, that is 1:15. The walls were cured for 7 days after which they were subjected to compressive test using a universal compression testing machine at the Structures and Building Materials of the University of Dar es Salaam. The test results are graphically presented in Figure 6 and the compressive stress in Figure 7.

\section{Load-displacement curves of crusher-dust masonry walls (1:15 ratio)}

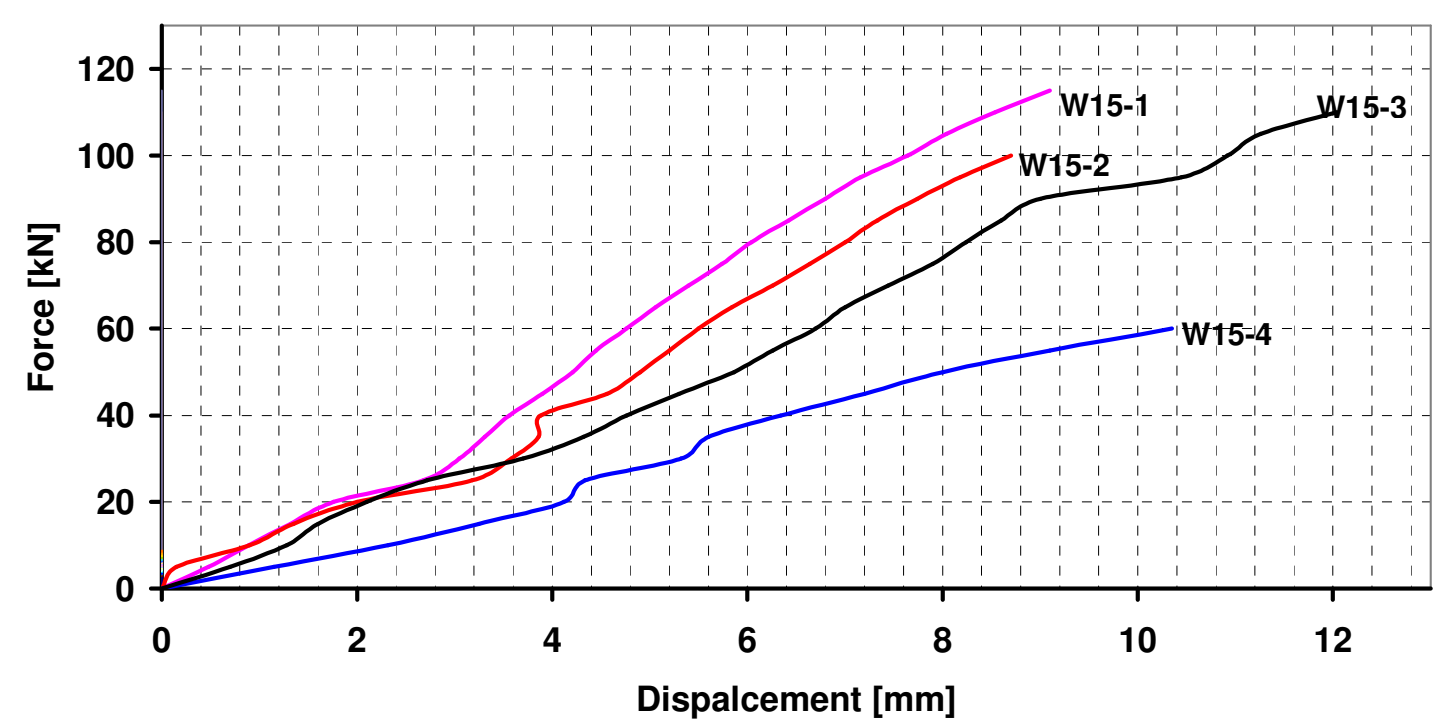

Figure 6: Graphical results for wall tests 
Basing on Figure 6, the minimum ultimate load was $60.0 \mathrm{kN}$. On conversion, this load is equal to $80.0 \mathrm{kN} / \mathrm{m}$. If the load is divided by an average partial safety factor of 1.5 , the characteristic load on the wall is $53.3 \mathrm{kN} / \mathrm{m}$. This load is quite high in traditional houses, therefore building using the crusher dust stabilized bricks, will lead into having walls which are sufficiently strong.
In Figure 7 , the compressive stresses of the walls are close to $1.0 \mathrm{~N} / \mathrm{mm}^{2}$ for walls 1,2 and 4 , while that of wall 3 is low having a value of $0.57 \mathrm{~N} / \mathrm{mm}^{2}$. Therefore, in case of a need for higher strength, then a mix ratio greater than 1:15 should be used, say $1: 12$ or $1: 10$, etc.

Compressive Strength of Walls [Ratio 1:15]

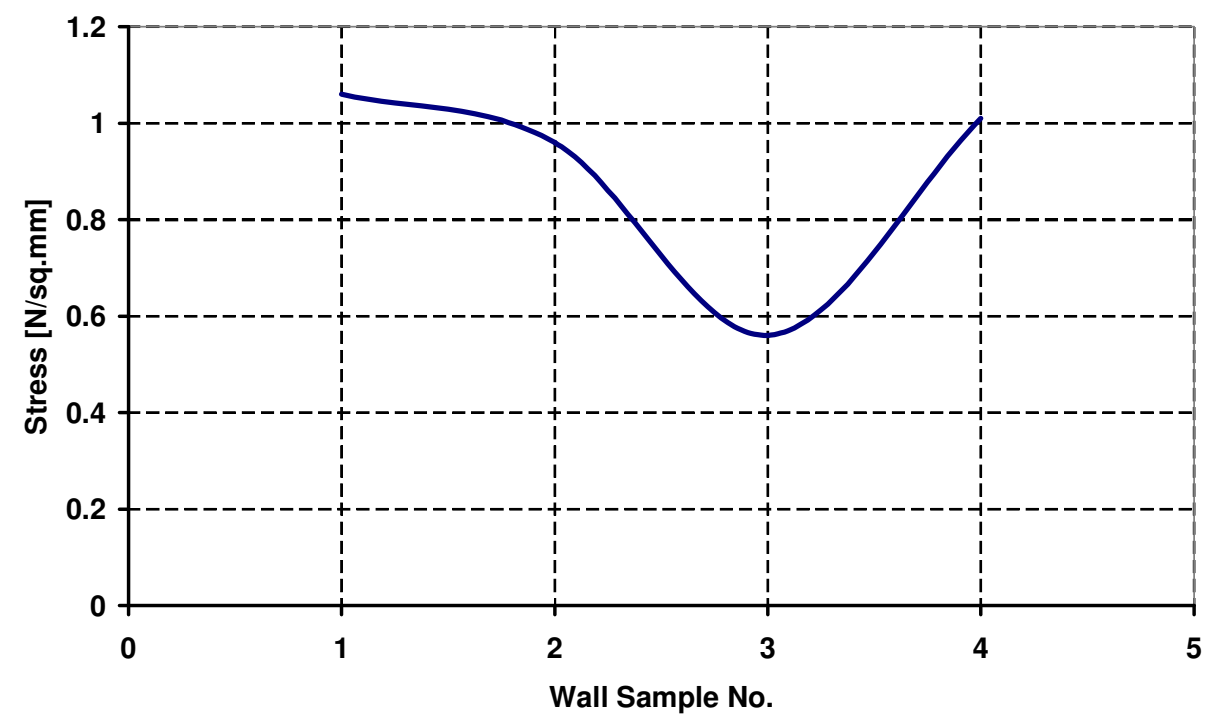

Figure 7: Strength of walls - ratio 1:15

\section{Compressive strength of mortar}

The mix ratio for the mortar was the same 1:15 (1 part cement : 15 parts crusher dust) that was used to manufacture the bricks. Only 3 cubes were prepared and cured for 7 days. Testing of their compressive strength was done when the age of the cubes was 28 days. The test results are presented in Table 4 below.

Table 4: Compressive strength of mortar (1:15 mix ratio)

\begin{tabular}{|c|c|c|c|c|c|c|c|c||}
\hline \multirow{2}{*}{$\begin{array}{c}\text { Sample } \\
\text { No. }\end{array}$} & \multicolumn{3}{|c|}{$\begin{array}{c}\text { Dimensions } \\
{[\mathrm{mm}]}\end{array}$} & $\begin{array}{c}\text { Weight } \\
{[\mathrm{kg}]}\end{array}$ & $\begin{array}{c}\text { Density } \\
{\left[\mathrm{kg} / \mathrm{m}^{3}\right]}\end{array}$ & $\begin{array}{c}\text { Area of } \\
\text { Compression } \\
{\left[\mathrm{mm}^{2}\right]}\end{array}$ & $\begin{array}{c}\text { Failure } \\
\text { Load } \\
{[\mathrm{kN}]}\end{array}$ & $\begin{array}{c}\text { Compressive } \\
\text { Stress }\left[\mathrm{N} / \mathrm{mm}^{2}\right]\end{array}$ \\
\cline { 2 - 6 } & $\mathrm{a}$ & $\mathrm{b}$ & $\mathrm{h}$ & & 10000 & 10.0 & 1.00 \\
\hline \hline 1 & 100 & 100 & 100 & 1.594 & 1597 & 100.5 & 1.04 \\
\hline 2 & 101 & 100 & 100 & 1.608 & 1592 & 10100 & 10.5 & 0.90 \\
\hline 3 & 100 & 100 & 100 & 1.594 & 1594 & 10000 & 9.0 & $\mathbf{0 . 9 8}$ \\
\hline
\end{tabular}




\section{Assessment of Durability Aspects}

Eight bricks were sampled in which four bricks from each mix ratio; i.e 1:10 and 1:15 were taken in order to test for water absorption and behaviour of the bricks under water. The bricks were submerged in water for 24 hours, then they were taken out from the water. Since the crusher dust material contains an amount of $30 \%$ fines, our hypothesis was that the bricks upon absorbing a lot of water would just crumble. But the outcome was that the bricks were still hard and in solid state, they didn't crumble when held by hand at all. The maximum water absorption was $18 \%$ which is acceptable because the ceiling is $20 \%$.

\subsection{Discussion On The Results}

\section{Sieve analysis results}

The sieve analysis results from the crusher dust have shown that the crusher dust particles grading is mainly between $0.15 \mathrm{~mm}$ to $2.36 \mathrm{~mm}$. According to the USCS classification the crusher dust is a medium sand (MS).

\section{Compressive strengths of elements due to a mix ratio of 1:10}

The strength of the bricks from a mix ratio of 1:10 (1 part cement to 10 parts crusher dust) ranges from $3.21 \mathrm{~N} / \mathrm{mm}^{2}$ to $3.81 \mathrm{~N} / \mathrm{mm}^{2}$. The average compressive strength of the bricks is $3.49 \mathrm{~N} / \mathrm{mm}^{2}$. The average density of 18.48 $\mathrm{kN} / \mathrm{m}^{3}$ as well as the density of each individual brick are slightly lower than the density of cement-sand blocks which range from $19-22 \mathrm{kN} / \mathrm{m}^{3}$.

From the results of wall tests, it has been found that the compressive strength varies from $1.28 \mathrm{~N} / \mathrm{mm}^{2}$ to $2.2 \mathrm{~N} / \mathrm{mm}^{2}$. The average compressive strength is $1.78 \mathrm{~N} / \mathrm{mm}^{2}$. The shortening of the walls ranges from $6.4 \mathrm{~mm}$ to $10.8 \mathrm{~mm}$. Two walls had their displacement not more than $6.8 \mathrm{~mm}$, one wall was displaced up to $8.2 \mathrm{~mm}$ while the last one reached a value of about $9.6 \mathrm{~mm}$.

The compressive strength results for the mortar of mix ratio $1: 10$ ranges from $0.75 \mathrm{~N} / \mathrm{mm}^{2}$ to $1.39 \mathrm{~N} / \mathrm{mm}^{2}$. The average compressive strength of the mortar is $1.06 \mathrm{~N} / \mathrm{mm}^{2}$. The densities of the mortar vary from $15.1 \mathrm{kN} / \mathrm{m}^{3}$ to $15.84 \mathrm{kN} / \mathrm{m}^{3}$. The average density is $15.61 \mathrm{kN} / \mathrm{m}^{3}$. It can be observed that the density of bricks is higher than that of the mortar because the bricks were manufactured by employing high compressive effort while the mortar was compacted by vibration using a shaking table.

\section{Compressive strengths of elements due to a mix ratio of 1:15}

The strength of the bricks from a ratio 1:15 (1 part cement to 15 parts crusher dust) ranges from $2.62 \mathrm{~N} / \mathrm{mm}^{2}$ to $3.93 \mathrm{~N} / \mathrm{mm}^{2}$. The average strength of the bricks is $3.20 \mathrm{~N} / \mathrm{mm}^{2}$. The average density of $18.26 \mathrm{kN} / \mathrm{m}^{3}$ is slightly lower than the density of bricks manufactured from a mix ratio of 1:10.

The compressive strength of the tested walls varies from $0.56 \mathrm{~N} / \mathrm{mm}^{2}$ to $1.06 \mathrm{~N} / \mathrm{mm}^{2}$. The average compressive strength is $0.90 \mathrm{~N} / \mathrm{mm}^{2}$. The displacements of the walls range from 8.6 $\mathrm{mm}$ to around $12.00 \mathrm{~mm}$. Two walls had their displacements less than $10 \mathrm{~mm}$, one wall displaced up to $10.4 \mathrm{~mm}$ while the largest displacement for wall W15-3 was $12.04 \mathrm{~mm}$.

The compressive strengths of the mortar range from $0.90 \mathrm{~N} / \mathrm{mm}^{2}$ to $1.04 \mathrm{~N} / \mathrm{mm}^{2}$, while the average compressive strength is $0.98 \mathrm{~N} / \mathrm{mm}^{2}$. The densities of the mortar vary from 15.92 $\mathrm{kN} / \mathrm{m}^{3}$ to $15.97 \mathrm{kN} / \mathrm{m}^{3}$. The average density is $15.94 \mathrm{kN} / \mathrm{m}^{3}$. The strength of the mortar as well as the density are slightly less than those obtained from the mix ratio of 1:10.

\section{Durability aspect}

The tested bricks didn't soften after being soaked in water for 24 hours, and had a normal water absorption of around $20 \%$. This implies that the walls will function well even during wet or rain season.

\subsection{Design}

The design of masonry structural elements such as walls, columns, beams, etc can be done basing on the British Standard BS 5628 Parts 1 and $2^{[6]}$ 


\subsection{CONCLUDING REMARKS}

From this study the following conclusions are drawn;

(i) The crusher dust has to be sieved in a $2.36 \mathrm{~mm}$ sieve in order to remove bigger particles which would diminish the bond characteristics of the soil.

(ii) The average density of the bricks from a mix ratio of $1: 10$ is $18.48 \mathrm{kN} / \mathrm{m}^{3}$ while the corresponding mortar has a density of $16.13 \mathrm{kN} / \mathrm{m}^{3}$.

(iii) The average density of the bricks from a mix ratio of $1: 15$ is $18.26 \mathrm{kN} / \mathrm{m}^{3}$ while the corresponding mortar has a density of $15.94 \mathrm{kN} / \mathrm{m}^{3}$.

(iv) The compressive strength of masonry walls built from bricks manufactured from a mix ratio of $1: 10$ is $1.78 \mathrm{~N} / \mathrm{mm}^{2}$.

(v) The compressive strength of masonry walls built from bricks manufactured from a mix ratio of $1: 15$ is $0.90 \mathrm{~N} / \mathrm{mm}^{2}$.

The following recommendations are deemed necessary upon abundant availability of crusher dust material:

(i) Crusher dust is a suitable material for bricks production. The produced bricks are sufficiently strong and demonstrate good durability behaviour.

(ii) Bricks made from stabilized crusher dust are cheaper in cost compared to cement/sand blocks because the crusher dust is cheaper than sand and the amount of cement used is lower than that used for cement-sand blocks. Hence this material should be used for construction purposes as it leads to lowcost housing.

(iii) If one desires much more higher strength, the ratio of cement to crusher dust should also be increased, say from 1:10 and above.

(iv) Further research on the availability of crusher dust material has to be carried out so as to establish the effects on the cost of buying. But up to this moment, the cost of an 18 tone lorry is still cheaper by about $50 \%$ of the cost of sand.

\subsection{REFERENCES}

1. Andrew Plumridge \& Wim Muelenkamp, "Brickwork", Studio Vista, 1993, London

2. A. Kezdi, "Stabilized Earth Roads", Elsevier Scientific Publishing Company, Amsterdam, 1979.

3. W.G.Curtin et al, [1984], "Structural Masonry Detailing", Granada Publishing, London.

4. Atkinson R.H. et al, [1983], “A proposed failure theory for brick masonry in compression", Proceedings, $3^{\text {rd }}$ Canadian Masonry Symposium, Edmonton, Canada, 1983, pp 5-1 - 5-17.

5. BS 5628: Part 1: 1985; Structural Use of Plain Masonry, BSI, London

6. BS 5628: Part 2: 1985; Structural Use of Reinforced Masonry, BSI, London 